\title{
Copper(II) Selective PVC Membrane Electrodes Based on Schiff base 1,2-Bis (E-2-hydroxy benzylidene amino)anthracene-9,10-dione Complex as an Ionophore
}

\author{
Eunseon Jeong, Hyo Kyoung Lee, ${ }^{\dagger}$ Mohammad Shamsuddin Ahmed, Hyungran Seo, and Seungwon Jeon* \\ Department of Chemistry and Institute of Basic Science, Chonnam National University, Gwangju 500-757, Korea \\ *E-mail: swjeon3380@naver.com \\ ${ }^{\dagger}$ Department of Biotechnology and Food Science, Mongolia International University, Ulaanbaatar 51, Mongolia \\ Received November 18, 2009, Accepted December 31, 2009
}

\begin{abstract}
The Schiff base 1,2-bis(E-2-hydroxy benzylidene amino)anthracene-9,10-dione has been synthesized and explored as ionophore for preparing PVC-based membrane sensors selective to the copper $\left(\mathrm{Cu}^{2+}\right)$ ion. Potentiometric investigations indicate high affinity of these receptors for copper ion. The best performance was shown by the membrane of composition (w/w) of ionophore: $1 \mathrm{mg}$, PVC: $33 \mathrm{mg}$, DOP: $66 \mathrm{mg}$ and KTpCIPB as additive were added $50 \mathrm{~mol} \%$ relative to the ionophore in $1 \mathrm{ml} \mathrm{THF}$. The proposed sensor's detection limit is $2.8 \times 10^{-7} \mathrm{M}$ over $\mathrm{pH} 5$ at room temperature (Nernstian slope $31.76 \mathrm{mV} / \mathrm{dec}$.) with a response time of 15 seconds and showed good selectivity to copper ion over a number of interfering cations.
\end{abstract}

Key Words: Schiff base, Copper-ion selective electrode, Potentiometry, Ionophore, 1,2-Bis(E-2-hydroxy benzylidene amino)anthracene-9,10-dione

\section{Introduction}

The Atlanta based Agency for Toxic Substances and Disease Registry (ATSDR) says their website that the copper is essential for good health. However, exposure to higher doses can be harmful. If people drink water that contains higher than normal levels of copper, they may experience nausea, vomiting, stomach cramps, or diarrhea. Intentionally high intakes of copper can cause liver and kidney damage and even death. No relation has been between copper toxicity and human cancer. The US Environmental Protection Agency (EPA) says their website last updated on September 12 th, 2009 that $1.3 \mathrm{mg} / \mathrm{L}$ is the highest level of a contaminant that is allowed in drinking water. EPA also says that the short term exposures would be affected from gastrointestinal distress and long term exposures might be affected from liver or kidney damage. Also it has influence on environmental pollution. The determination of trace amounts of copper becomes increasingly important. So that it is necessary to determine the copper ion concentration in natural drinking water and imported food. In the mean time we feel interest to introduce an effective and fast working Schiff base PVC based membrane electrode. The ion selective electrodes (ISEs) permit the potentiometric measurement of the activity of a given ion in the presence of other ions. Synthesis and then application of an ion selective electrode as a potentiometric sensor offers interesting advantages over the traditional methods of analysis such as easy to preparation and procedures, simple instrumentation, relatively fast response, wide dynamic range, reasonable selectivity and low cost. ${ }^{1}$

Moreover they provide accurate, reproducible and often selective determination of various ionic species. Not only this, the ion-selective electrodes (ISEs) allow nondestructive, on line monitoring of particular ion in small volume of sample without any pretreatment. Because of these merits, the use of ISEs are increasing day by day in different fields. Now a days electro- conducting polymers are widely used in the solid-state ion selective electrodes. ${ }^{2,3}$ Because of mixed ionic and electronic conductivity, these materials generate electric response to the changes in the content of the potential determining species. The incorporation of conducting polymer into the surface coating of the ion-selective sensor simplifies its manufacture by reason of the elimination of internal filling and stabilizes the response due to the suppression of the effect of dissolved oxygen and plastic membrane leaching. ${ }^{4}$ Loads of metal chelators are based on crown-type ligands which usually are full of $\mathrm{O}, \mathrm{N}$, or $\mathrm{S}$ donor atoms, and they are often employed as ionophores in ion-selective electrodes. ${ }^{5}$ PVC-based film ion selective electrodes are now well established analytical tools routinely used for chemical, biological and environmental analysis of a wide variety of different ions. ${ }^{6-9}$ It is well known that the important component of PVC membranes is the carrier that determines the selectivity of the electrodes. By reason of their electrical neutrality, lipophilic character, and capability to selectively and reversibly bind with metal ions. Microcyclic compounds have considerable attention for the development of carrier-based PVC membrane sensors sensitive toward cationic species. ${ }^{6-12}$ Different number of the microcyclic ring or replacing atoms by nitrogen atoms in the microcyclic ring, the affinity will be expected to be toward heavy or transition metal cations. ${ }^{13}$ On the other hand, by using aza-macro compounds as neutral carriers in PVC membranes, highly selective electrodes for heavy and transition metal cations and copper ion have been developed. ${ }^{14-16}$ Many Schiff bases have been studied as carriers for various metal ion-selective electrodes. A variety of ion carriers have been used to construct copper(II) selective electrodes. These copper ion carriers include small size thiacrown ethers, ${ }^{17,18}$ non-cyclic neutral ionophores containing dithiocarbamate groups, ${ }^{19,20}$ nitrogen atom, ${ }^{21}$ calix[4] arenes ${ }^{22}$ and Schiff base. ${ }^{16}$ In this study, we prepare PVC membrane electrodes based on Schiff base 1,2-bis(E-2-hydroxy benzylidene amino)anthracene-9,10-dione synthesized 
as an ionophore and were used for the determination of copper ion. The proposed sensor revealed good selectivity and response for $\mathrm{Cu}^{2+}$ over a wide variety of other interfering metal ions .

\section{Experimental}

Reagents. 1,2-Bis(E-2-hydroxy benzylidene amino)anthracene-9,10-dione (Figure 1) tested as copper ionophore was prepared according to the procedure described previously. ${ }^{23}$ High molecular weight PVC was purchased from Fluka, dioctyl sebacate (DOS), dioctyl adipate (DOA), dioctyl phthalate (DOP), 2nitrophenyl octyl ether (o-NPOE), potassium tetrakis (4-chlorophenyl) borate $(\mathrm{KT} p \mathrm{ClPB})$ and tetrahydrofuran(THF) were purchased from Aldrich, were used to prepare the PVC membranes. The nitrate salts of cations used (all from Merck) were used without any further purification. Doubly distilled water in a quartz apparatus was used to preparation of all aqueous electrolyte solutions.

Preparation of polymeric ion-selective electrodes. The compositions of PVC-based copper-selective electrodes were summarized in Table 1, and the typical one (m-8) was $33 \mathrm{mg}$ PVC, $66 \mathrm{mg}$ plasticizer, $1 \mathrm{mg}$ ionophore and $\mathrm{KT} p \mathrm{ClPB}(50 \mathrm{~mol} \%$ of ionophore). The ionophore, plasticizer and PVC were dissolved in the appropriate volume of THF and mechanically stirred. All membrane cocktails were cast in glass rings placed on glass plates for conventional ionselective electrodes. Solvent from PVC membrane was allowed to evaporate for at least 24 hours at room temperature. The thickness of the resulting membrane measured by micrometer was about $0.3 \mathrm{~mm}$.

Potentiometric measurements. The electrochemical properties of copper-selective electrodes were investigated in the conventional configuration. Small disks were punched from the cast membranes and mounted in Philips electrode bodies (IS-561). For all electrodes, $0.1 \mathrm{M} \mathrm{KCl}$ solution was used as an internal filling solution. All electrodes were finally conditioned for 24 $\mathrm{h}$ by soaking in $1.0 \times 10^{-2} \mathrm{M} \mathrm{Cu}\left(\mathrm{NO}_{3}\right)_{2}$ solution. $\mathrm{A} \mathrm{Ag} / \mathrm{AgCl}$ coated wire was used as an internal reference electrode. The external reference electrode was an Orion sleeve-type doublejunction $\mathrm{Ag} / \mathrm{AgCl}$ reference electrode (Model 90 - 20) with two

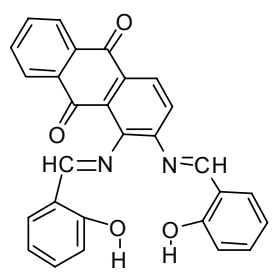

Figure 1. The structure of 1,2-bis(E-2-hydroxy benzylidene amino) anthracene-9,10-dione.

chambers. This reference electrode has two different filling solution: inner chamber filling solution is green colored solution saturated with $\mathrm{AgCl}$, outer chamber filling solution consists of $10 \% \mathrm{KNO}_{3}$. The potential measurements were carried out at $25 \pm 1{ }^{\circ} \mathrm{C}$ with Kosentech 16-channel potentiometer (KST101-1) coupled to a computer by setting up the following cell assembly: $\mathrm{Ag} / \mathrm{AgCl} \mid 0.1 \mathrm{M} \mathrm{KNO}_{3}$ || $0.05 \mathrm{M}$ Tris- $\mathrm{HCl}$ (sample solution) $\|$ PVC membrane $\mid$ Internal filling solution $(0.1 \mathrm{MKCl}) \mid \mathrm{AgCl} / \mathrm{Ag}$. The electrochemical measurements were conducted after within $1 \mathrm{mV}$ variance of open circuit potential with 5 minutes. The dynamic response curves were produced by adding standard solutions of cations to magnetically stirred $\mathrm{pH} 5$ buffer solution (0.05 M Tris (hydroxymethyl) aminomethane-HCl). The selectivity coefficients $\left(\log \mathrm{K}_{\mathrm{Cu}^{2+} \mathrm{j}}^{\mathrm{pot}}\right)$ were determined by the separate solution method (SSM) using nitrate salts of the cations involved. Detection limits were estimated at the intersection of two linear lines, the one extrapolated from a high concentration range and the other parallel to the X-axis drawn through the mean potential value of the lowest metal ion concentration used in the plot of the potential change and the concentration of $\mathrm{Cu}^{2+}$.

\section{Results and Discussion}

Schiff bases as ligands seem to be a potential ionophore for soft heavy metal ions in the PVC membrane electrodes, because of its excellent metal-binding properties, rapid exchange kinetics, and water insolublilty. ${ }^{24-25} 1,2-\mathrm{Bis}(E$-2-hydroxy benzylidene amino)anthracene-9,10-dione was used as an ionophore for

Table 1. The compositions of membranes and their potentiometric characteristics of the copper-selective electrode over $\mathrm{pH} 5$.

\begin{tabular}{|c|c|c|c|c|c|c|c|}
\hline Membrane & $o-\mathrm{NPOE}^{a}$ & $\mathrm{DOA}^{a}$ & $\mathrm{DOP}^{a}$ & $\operatorname{DOS}^{a}$ & $\mathrm{KT}_{p} \mathrm{ClPB}^{b}$ & LOD & Slope $(\mathrm{mV})$ \\
\hline$m-1$ & 66 & & & & 0 & -5.36 & 16.48 \\
\hline$m-2$ & 66 & & & & 50 & -5.88 & 27.07 \\
\hline$m-3$ & 66 & & & & 100 & -4.60 & 28.03 \\
\hline$m-4$ & & 66 & & & 50 & -3.88 & 9.25 \\
\hline$m-5$ & & 66 & & & 100 & -5.13 & 25.69 \\
\hline$m-6$ & & & 66 & & 0 & -6.17 & 21.84 \\
\hline $\mathrm{m}-7$ & & & 66 & & 20 & -5.99 & 34.82 \\
\hline m-8 & & & 66 & & 50 & -6.60 & 31.76 \\
\hline$m-9$ & & & 66 & & 100 & -5.00 & 24.02 \\
\hline$m-10$ & & & & 66 & 0 & -5.75 & 29.92 \\
\hline $\mathrm{m}-11$ & & & & 66 & 50 & -6.23 & 40.05 \\
\hline$m-12$ & & & & 66 & 100 & -4.71 & 17.05 \\
\hline
\end{tabular}

All membranes are comprised of ionophore $1 \mathrm{mg}$ and PVC $33 \mathrm{mg} .{ }^{a}$ in $\mathrm{mg} .{ }^{b}$ in $\mathrm{mol} \%$ relative to the ionophore. 


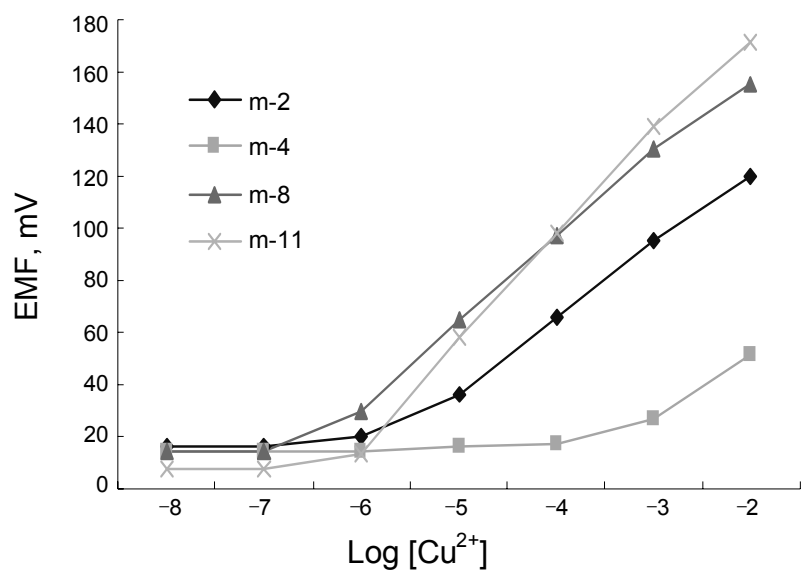

Figure 2. Potentiometric responses of the membrane prepared from different plasticizers with ionophore towards $\mathrm{Cu}^{2+}$.

preparing PVC membrane ion-selective electrodes for a wide variety of metal ions. We said in our previous study ${ }^{16}$ that the $\mathrm{Cu}^{2+}$ ISE membrane compositions were optimized to produce the best sensitivity and selectivity towards copper ion, because the sensitivity of the ion-selective electrodes depend on the nature of ionophore used as well as significantly on the membrane compositions and selectivity of the electrodes depends on the nature of ionophore. The optimization was carried out with varying of the ratio in PVC membrane components such as plasticizer and additive (KTpClPB).

The Schiff base 1,2-bis( $E$-2-hydroxy benzylidene amino)anthracene-9,10-dione was employed as copper selective ionophore in the preparation of copper ion selective electrode. The responses of the four electrodes (with different plasticizer) are shown in Figure 2. The electrodes of $\mathrm{m}-2, \mathrm{~m}-8$ and $\mathrm{m}-11$ exhibit wider linear response range, and m- 8 has closer Nernstian slope among them.

The polymeric membranes are investigated to measure the ability of the ionophore to act as an ion carrier in the absence and presence of the ion exchanger. The response of the membranes without additive ion-exchanger (KTpClPB) gave the worse sensitivity and selectivity than those with $\mathrm{KT} p \mathrm{ClPB}$. Most of membrane electrodes were prepared with $\mathrm{KT} p \mathrm{ClPB}$ in this work. The potentiometric response of the membranes was evaluated as to the slope and detection limit towards copper ion. The slope and detection limit for membranes were determined in accordance with IUPAC recommendations. ${ }^{26}$ Figure 3 illustrates typical response curves for copper ion, measured in $\mathrm{pH} 5.0$ buffer solution by membranes (m-6, m-7, m-8, m-9) containing different amount of additive (KTpClPB), respectively. They show that the ionophore gives best sensitivity towards copper ion containing in $50 \mathrm{~mol} \%$ additives. The effects of the membrane composition, the nature of plasticizers, ionophores, and lipophilic additive on the potentiometric response of the $\mathrm{Cu}^{2+}$ ISE were summarized and investigated in Table 1 . The membrane (m-8) prepared by DOP as a plasticizers, $50 \mathrm{~mol} \%$ of additive displays a good Nernstian response to $\mathrm{Cu}^{2+}$ over the wide range. The slope of the calibration curve was $31.76 \mathrm{mV} / \mathrm{de}-$ cade for $\mathrm{Cu}^{2+}$ at room temperature, and the limit of detection (LOD) is $2.8 \times 10^{-7} \mathrm{M}$. The different slope can be attributed to

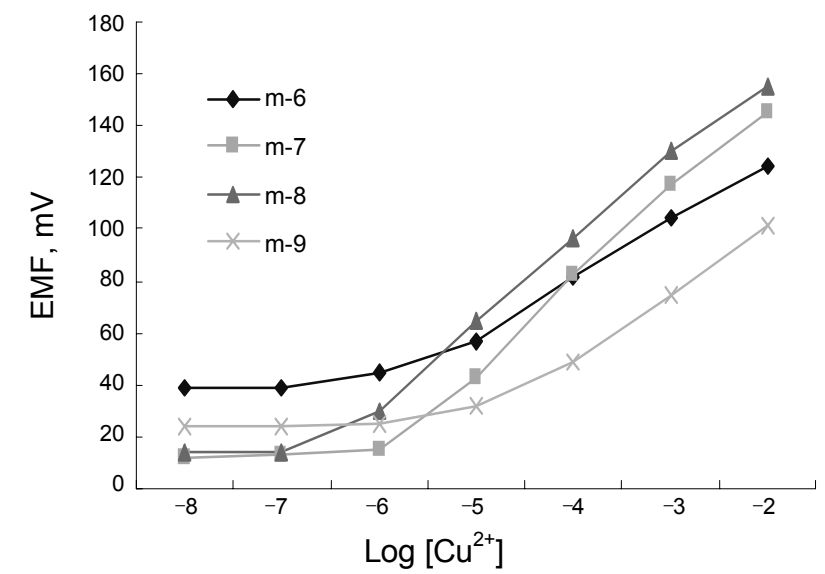

Figure 3. Response curves of membranes containing different $\%$ of additive measured over $\mathrm{pH} 5$.

the complication factor and sensing rate according to the membrane formulation. It should be noted that the presence of lipophilic anions in cation-selective membrane electrodes provides the decrease of the ohmic resistance as well as the improvement of their sensitivity and selectivity.

The selectivity coefficients of the new membranes are very important for determining their quality as ISEs. The selectivity coefficients represent their response to the species to be measured over other ions present in solution. The selectivity coefficients of the electrodes were determined by the separate solution method (SSM). They were evaluated by the separate solution method. The selectivity coefficients towards $\mathrm{Cu}^{2+}$ were determined against the interfering cations, $\mathrm{Pb}^{2+}, \mathrm{Co}^{2+}, \mathrm{Cd}^{2+}, \mathrm{Mn}^{2+}$, $\mathrm{Zn}^{2+}, \mathrm{Mg}^{2+}, \mathrm{Ca}^{2+}, \mathrm{Sr}^{2+}, \mathrm{Ni}^{2+}, \mathrm{Ba}^{2+}$. The selectivity coefficients $\left(\log \mathrm{K}_{\mathrm{Cu}^{2} \mathrm{j}}^{\mathrm{pot}}\right)$ with respect to the corresponding nitrate over interfering ions tested are shown in Table 2. From these, it can be considered that 1,2-bis( $E$-2-hydroxy benzylidene amino)anthracene-9,10-dione as an ionophore employed is selective towards copper ion against above interfering ions. Among all membranes tested, the best result was obtained from $m-8$. As can be seen, with the exception of $\mathrm{Cu}^{2+}$, for all diverse ions used, the selectivity coefficients are in the order of $10^{-3}$ or smaller, indicating that they could not significantly disturb to the functioning of the $\mathrm{Cu}^{2+}$ selective electrode. It should be noted that $\mathrm{Mn}^{2+}$ provides negligible interference $(-\log =3.13)$ for the determination of copper ion. Thus, it is clear that the membrane electrode has good selectivity over and divalent cations. Meanwhile, the effect of counter anions was investigated using the copper salts of chloride and nitrate, indicating that no significant changes in the working concentration range and slope were observed. The selectivity data for the electrode (m-8) employed in this study indicates that the extent of complex formation between ionophore and metal ion and the geometrical structure are the major factors determining the selectivity. The result indicates that the geometry and legating cavity of the 1,2-bis $(E-2$-hydroxy benzylidene amino) anthracene-9,10-dione should be significant factor for determining a selectivity toward others. Based on data of $\mathrm{m}-8$ in Table 1 and 2, the good sensitivity and highest selectivity towards copper ion are attributed to the strong complexation of copper ion to 1,2-bis( $E$-2-hydroxy benzylidene ami- 
Table 2. Selectivity coefficients over various interfering ions for membrane (m-8) electrode.

\begin{tabular}{ccccccccccccc}
\hline \multicolumn{11}{c}{$\log \mathrm{K}_{\mathrm{Cu}^{+2}}^{\text {pot }}$} \\
\hline \multirow{2}{*}{$\mathrm{m}-8$} & $\mathrm{Cu}^{2+}$ & $\mathrm{Co}^{2+}$ & $\mathrm{Mn}^{2+}$ & $\mathrm{Ni}^{2+}$ & $\mathrm{Sr}^{2+}$ & $\mathrm{Ba}^{2+}$ & $\mathrm{Cd}^{2+}$ & $\mathrm{Zn}^{2+}$ & $\mathrm{Ca}^{2+}$ & $\mathrm{Mg}^{2+}$ & $\mathrm{Pb}^{2+}$ \\
& 0 & -3.87 & -3.13 & -3.61 & -4.05 & -3.88 & -3.74 & -3.61 & -3.83 & -3.52 & -3.47 \\
\hline
\end{tabular}

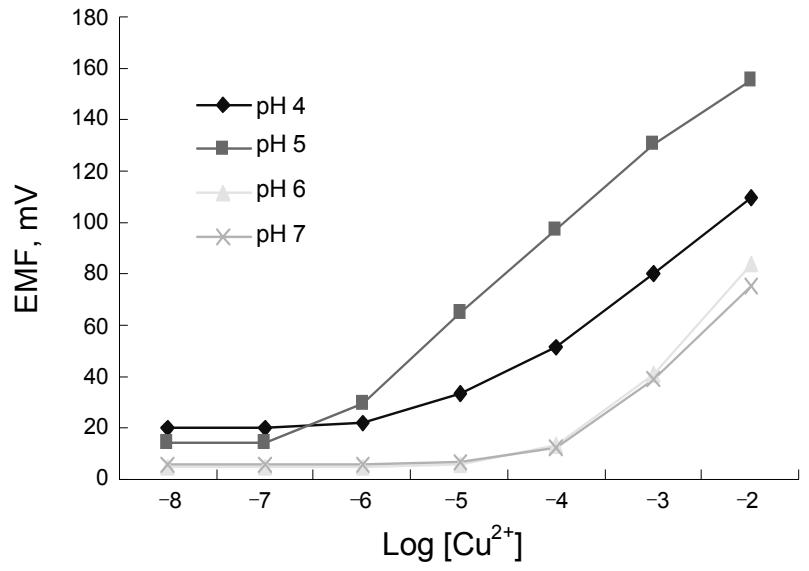

Figure 4. Potentiometric responses of the $\mathrm{Cu}^{2+}$ ISE membrane $(\mathrm{m}-8)$ over different $\mathrm{pH}$.

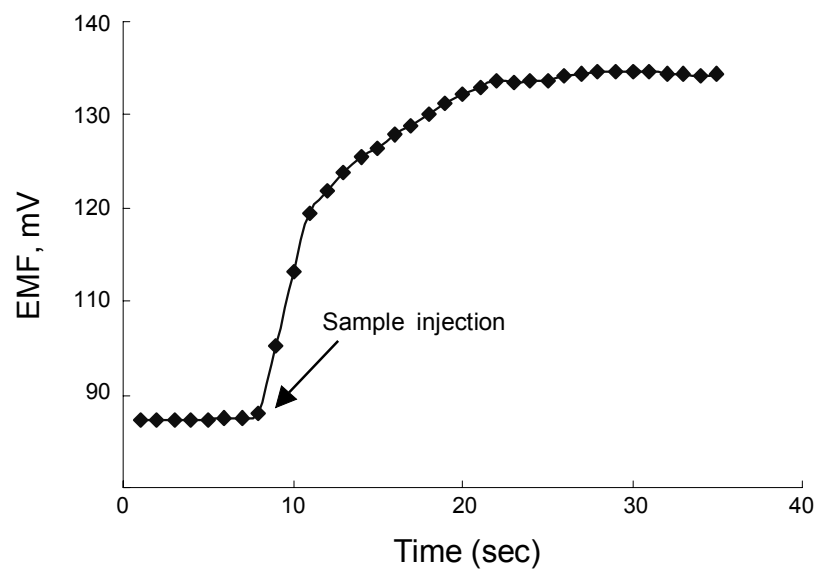

Figure 5. Response-time profile of the $\mathrm{Cu}^{2+}$ ISE membrane $(\mathrm{m}-8)$.

no)anthracene-9,10-dione which has geometrically the proper cavity to coordinate to the ligand, and its complexation with other cations should be weaker than the copper complexation. The electrode was applied to the direct measurement of $\mathrm{Cu}^{2+}$ in prepared solutions.

The potential was measured by direct potentiometry in $\mathrm{pH}$ 5.0 buffer solution. The $\mathrm{pH}$ dependence on the potentiometric response of the novel membrane electrode $(\mathrm{m}-8)$ is studied in a variety of $\mathrm{pH}$ solutions and shown in Figure 4 . The results indicate that the potentiometric response for $\mathrm{m}-8$ electrode depends on the solution $\mathrm{pH}$ employed, but the potential obtained from $\mathrm{m}-8$ electrode gives a similar value between $\mathrm{pH} 6$ and $\mathrm{pH} 7$. Therefore, the potentiometric response of PVC polymeric $\mathrm{Cu}^{2+}$ ISEs based on 1,2-bis(E-2-hydroxy benzylidene amino)anthracene-9,10-dione was examined for many metal ions in $\mathrm{pH} 5.0$ buffer solution in order to avoid the formation of metal-hydro- xide complex at higher $\mathrm{pH}$.

A potential-time plot for the electrode is shown in Figure 5. The static response time of the membrane electrode thus obtained was $<20 \mathrm{sec}$ for the increased concentration from $1.0 \times$ $10^{-3} \mathrm{M}$ to $1.0 \times 10^{-4} \mathrm{M}$ copper ion solution, indicating that the equilibrium can reach very quickly in $\mathrm{pH}$. The membranes responded rapidly to change in copper concentration within $15 \mathrm{~s}$.

The prolonged stability of these membranes was measured as a function of time; it was evidenced in both the slopes of the calibration curve and the detection limits. The membranes would be stored in $\mathrm{pH} 5.0$ buffer solution when not in use. After two weeks, the electrodes were responding at $96 \%$ of the initial response. By the end of one month, the response observed was still responding at $92 \%$ of the initial value.

\section{Conclusion}

As a final point, the membrane electrode incorporating 1,2bis(E-2-hydroxy benzylidene amino)anthracene-9,10-dione as an ion carrier can be used for the development of a copper ionselective electrode. Among membranes tested, polymeric membrane $\mathrm{m}-8$ based on 1,2-bis( $E$-2-hydroxy benzylidene amino)anthracene-9,10-dione with DOP and liphophilic additive of 50 $\mathrm{mol} \%$ displays a good Nernstian response $(31.76 \mathrm{mV} /$ decade $)$ over $\mathrm{pH} 5$ at room temperature to $\mathrm{Cu}^{2+}$ ion and the limit of detection of $2.8 \times 10^{-7} \mathrm{M}$ within short time $15 \mathrm{~s}$. Most of metal ions could not hamper the selectivity to the copper ion. It can be concluded that the membrane electrode has a rapid potential response and excellent selectivity towards copper ion over other interfering metal ions. It could be used successfully for the determination of copper ion content in environmental and waste water samples.

Acknowledgments. This work has been done by a Special Research Foundation Grant funded by Chonnam National University (2009).

\section{References}

1. Ardakani, M. M.; Dehghani, H.; Jalayer, M.; Zari, H. R. Anal. Sci. 2004, 20, 1667.

2. Bobacka, J.; Ivaska, A.; Lewenstam, A. Electroanalysis 2003, 15, 366.

3. Buck, R. Ion-Selective Electrodes in Analytical Chemistry; Plenum Press: New York, 1978.

4. Lindfors T.; Ivaska, A. Anal. Chim. Acta 2000, 404, 111.

5. Goldcamp, M. J.; Ashley, K.; Edison, S. E.; Pretty, J.; Shumakerc, J. Electroanalysis 2005, 17, 1015.

6. Ohki, A.; Lu, J. P.; Bartsch J. P. Anal. Chem. 1994, 66, 651.

7. Daunert, S.; Bachas, L. G. Anal. Chem. 1990, 62, 1428.

8. Moody, G. J.; Saad, B. B.; Thomas, J. D. R. Sel. Electrode Rev. 1988, 10,71 .

9. Ito, T. Anal. Sci. 1998, 14, 89.

10. Mashhadizadeh, M. H.; Shamsipur, M. Anal. Chim. Acta 1999, 
381,111 .

11. Mahajan, R. K.; Kumar, M.; Sharma, V.; Kaur, T. Analyst 2001, 126, 505.

12. Perez-Marin, L.; Lopez-Valdivia, H.; Avila-Perez, P.; Otazo-Sanchez, E.; Macedo-Miranda, G.; Gutierrez-Lozano, O.; Alonso, J.; De Torres-Orazco, J.; Carapia-Morales, L. Analyst 2001, 126, 501.

13. Isildak1, I.; Yolcu, M.; Isildak, O.; Demirel, N.; Topal, G.; Hosgoren, H. Microchim. Acta 2004, 144, 177.

14. Tavakkoli, N.; Shamsipur, M. Anal. Lett. 1996, 29, 2269.

15. Shamsipur, M.; Poursaberi, T; Rouhani, S.; Nicham, K.; Sharghi, H.; Ganjali, M. R. Anal Sci. 2000, 17, 1049.

16. Jeong, D. C.; Lee, H. K.; Jeon, S. Bull. Korean Chem. Soc. 2006, 27, 1593.

17. Kamata, S.; Yamasaki, K.; Higo, M.; Bhale, A.; Fukanaga, Y. Analyst 1988, 113, 45.
18. Casabo, J.; Mestres, L.; Escriche, L.; Texidor, F.; Perez-Jimenez, C. Chem. Soc., Dalton Trans. 1991, 1961.

19. Kamata, S.; Bhale, A.; Fukanaga, Y.; Murata, H. Anal. Chem. 1988, 60, 2464.

20. Kamata, S.; Murata, H.; Kubo, Y.; Bhale, A. Analyst 1989, 114, 1029.

21. Bazooka, Z. Analyst 1988, 113, 1893.

22. Cobber, P. L. H. M.; Gherkin, R. J. M.; Boomer, J. B.; Barged, P.; Vroom, W.; Reinhoudt, D. N. J. Am. Chem. Soc. 1992, 114, 10573.

23. Jeong, T.; Lee, H. K.; Jeong, D. C.; Jeon, S. Talanta 2005, 65, 543.

24. Alizadeh, N.; Ershad, S.; Naeimi, H.; Sharghi, H.; Shamsipur, M.; Fresenius' J. Anal. Chem. 1999, 365, 511.

25. Gupta, K. C.; D'Arc, M. J. Anal. Chim. Acta 2001, 437, 199.

26. IUPAC Analytical Chemistry Division, Commission on Analytical Nomenclature. Pure Appl. Chem. 1976, 48, 127. 